\section{Mapeando programas de redução de danos da Região Metropolitana de Porto Alegre, Rio Grande do Sul, Brasil}

\author{
Mapping harm reduction programs in Greater \\ Metropolitan Porto Alegre, Rio Grande do Sul \\ State, Brazil
}

\footnotetext{
1 Programa de PósGraduação em Psicologia Social e Institucional, Universidade Federal do Rio Grande do Sul, Porto Alegre, Brasil.

2 Laboratório de Psicologia e Políticas Públicas,

Universidade Federal do Rio Grande do Sul, Porto Alegre, Brasil.

3 Universidade Regional Integrada do Alto Uruguai e das Missões, Santiago, Brasil.

Correspondência

R. Q. Rigoni

Universidade Regional

Integrada do Alto Uruguai e das Missões.

Rua Visconde do Herval 334 apto. 21, Porto Alegre, RS 90130-150, Brasil.

rafaelaqr@yahoo.com.br
}

\section{Abstract}

This study mapped and described 11 harm reduction interventions/programs in Greater Metropolitan Porto Alegre, Rio Grande do Sul State, Brazil, in 2004-2006. Mapping was based on interviews and analysis of available documents and comparison with a previous study with data from 2003. We aimed to discuss the programs' sustainability (political, financial, and administrative) and operational characteristics, based on the following categories: type of links in the program or intervention; forms of inclusion in the municipalities; background, financing; typical activities; team hiring practices; volunteer work, if any; resources (human and financial); partnerships; municipal legislation, if any; and participation in forums for political representation. Despite the diversity of links and organizational formats, there were some common characteristics: precarious professional status; dependence on volunteer work to implement activities; influence of turnover in Municipal and State administration on the continuity of projects and partnerships, as well as on the maintenance of human and financial resources. We conclude that such factors lead to lack of continuity in the services provided to the target population.

Harm Reduction; Street Drugs; Public Policies
Henrique Caetano Nardi 1,2

Rafaela de Quadros Rigoni 2,3

\section{Introdução}

A redução de danos se constitui como estratégia que incentiva a busca por uma saúde possível para usuários de drogas e seus familiares, servindo como instrumento de luta pela garantia de seus direitos. Por ser um conjunto de medidas para minimizar os danos decorrentes do uso/abuso de drogas, sem que haja, necessariamente, uma diminuição do consumo, tais ações possuem como princípio o respeito à "liberdade de escolha", pois nem todos os usuários conseguem ou desejam abster-se do uso de drogas 1 .

A implantação da redução de danos no Brasil deu-se há 17 anos, quando surgiram as primeiras iniciativas em São Paulo (onde a continuidade foi impedida por conta de uma interdição judicial) 2 e 12 anos da implantação oficial, em Salvador, Bahia, no ano de $1995^{3}$. No Estado do Rio Grande do Sul, em Porto Alegre, iniciouse em 1996 um projeto de redução de danos 4, oficializado em 19975 pela sua institucionalização e financiamento pela política municipal de DST/AIDS. Já a regulamentação do trabalho aconteceu em 1999, com a aprovação do Projeto de Lei no. 169/19999 6.

Os Programas de Redução de Danos (PRD) são a forma predominante de implantação da estratégia de redução de danos no Brasil, consistindo em uma variedade de ações desenvolvidas nas comunidades por agentes comunitários especiais, chamados "redutores de danos" 3. 
Estas ações incluem a troca e distribuição de seringas (para usuários de drogas injetáveis-UDI), preservativos, cachimbos (para o uso de crack), atividades de informação, educação e comunicação, aconselhamento, encaminhamento, reuniões comunitárias, dentre outros ${ }^{3,7}$. Tal gama de atividades é fruto de anos de modificações sucessivas, com base na experiência prática, de novas necessidades em função das modificações no cenário de uso/abuso de drogas e da avaliação e monitoramento do trabalho dos PRD em todo o mundo ${ }^{8}$. Podemos localizar na Holanda o início dos Programas de Trocas de Seringas (PTS). Os PTS passaram a ampliar progressivamente suas atividades, uma vez que somente a provisão de seringas não se mostrou suficiente para alterar significativamente o comportamento de risco dos UDI, sendo necessário investir em ações intensivas de aconselhamento ${ }^{9}$. A maioria dos programas fora do Brasil continua chamando-se PTS, sendo nosso país uma exceção neste sentido 10,11 .

O crescimento e a diversificação das ações nos PRD trouxeram novos desafios e configurações do trabalho, relacionados à ampliação da abordagem em campo e à busca por outras formas de sustentar ações e trabalhadores 12 . Apesar do crescimento do número de programas/ ações financiados e da diversificação das fontes financiadoras e parcerias, muitas dificuldades ligadas à sustentabilidade política, técnico-administrativa e financeira ainda são encontradas, tornando-se importante as trocas de informação entre os locais para incentivar reflexões e saídas coletivas 12 .

Na Região Metropolitana de Porto Alegre, diversos encontros e fóruns vêm sendo realizados pelos atores do movimento social em redução de danos para discutir estas questões, e muitos avanços ocorreram no plano das ações realizadas 13. No âmbito governamental, a pedido da Seção Estadual de DST/AIDS (SE-DST/AIDS) e do Centro de Referência para o Assessoramento e Educação em Redução de Danos da Escola de Saúde Pública do Estado do Rio Grande do Sul (CRRD-ESP/RS), realizou-se em 2003 uma análise da situação em que se encontravam os PRD no Rio Grande do Sul, com o objetivo de monitorar, avaliar e planejar políticas públicas neste campo 13 .

O relatório resultante dessas análises, embora debatido com os respectivos $\mathrm{PRD}$, não foi publicado como geralmente acontece com aqueles realizados nas demais regiões e em âmbito nacional. Os dados produzidos raramente são devolvidos de forma eficiente aos programas para que os eles possam avaliar suas ações e criar estratégias. Apresenta-se uma dificuldade de transferência de conhecimento, ou aprendizado em políticas públicas, uma vez que os formuladores destas políticas geralmente devem agir em circunstâncias nas quais sua informação e recursos são deficientes, produzindo uma estratégia limitada. Ademais, a comunicação não implica a exata reprodução das informações, mas um processo de interpretação, que é imperfeito 14.

Também no âmbito acadêmico, raros são os estudos dedicados à descrição ou mapeamento das diferentes formas de funcionamento desenvolvidas pelos PRD 11, ou seja, a descrição das características dos programas e ações em redução de danos quanto à situação política de implementação, financiamento, histórico, relações de trabalho, contexto legal, atividades desenvolvidas, parcerias, distribuição geográfica. Poucos também são os estudos que se envolvem com a discussão relativa aos trabalhadores da redução de danos 15,16.

\section{Metodologia}

Este artigo tem como objetivo descrever a forma de funcionamento das ações e programas de redução de danos desenvolvidas nos municípios da Região Metropolitana de Porto Alegre, entre 2004 e 2006. O material apresentado corresponde ao mapeamento dos 11 programas/ações então vigentes na região. As informações coletadas buscaram compreender o panorama geral da redução de danos na Região Metropolitana de Porto Alegre, a saber: as formas de inserção da redução de danos nos municípios; o tempo de vida dos diferentes programas; as diferentes formas de financiamento e contratação da equipe e redutores; as atividades realizadas; a infra-estrutura; os critérios de entrada dos trabalhadores; a existência de trabalho voluntário; as parcerias estabelecidas; a existência de legislação específica para a redução de danos nos municípios; e a participação em espaços de representação política referente à saúde e às drogas.

Em maio de 2006, o Rio Grande do Sul possuía 26 programas/ações em redução de danos em funcionamento, sendo 15 PRD ligados a municípios (organizações governamentais) e os demais projetos de organizações não governamentais (ONG). Na Região Metropolitana de Porto Alegre, eram nove os programas/ações financiados. No desenvolvimento da pesquisa novos programas/ ações surgiram e outros foram suspensos, mostrando o caráter muitas vezes frágil das intervenções por projetos.

No período de março a setembro de 2005, investigamos 11 programas/ações situados na Região Metropolitana de Porto Alegre nas cidades 
de Alvorada, Cachoeirinha, Canoas, Charqueadas, Gravataí, Parobé, Porto Alegre, São Leopoldo e Viamão. Nos casos onde foi possível, utilizamos a análise dos PRD realizada no estado em 2003 como base para comparação 13 , a fim de poder observar continuidades e descontinuidades presentes nas histórias dos programas.

Os programas e ações em redução de danos apresentam diferentes formas de organização do trabalho. Um PRD possui uma estrutura de equipe e trabalho, contando com uma coordenação, geralmente responsável por questões burocráticas e políticas, e uma equipe de redutores, responsável pelo trabalho de campo na comunidade. Já um local que conta com “ações” não possui um programa estruturado e/ou desenvolve trabalho com redução de danos fora destes moldes, realizando apenas intervenções pontuais na comunidade por intermédio de lideranças comunitárias ou um trabalho mediado pelos agentes comunitários de saúde (ACS) dos Programas de Agentes Comunitários de Saúde (PACS) e Programas Saúde da Família (PSF) municipais. Assim, a divisão entre programas e ações reflete, respectivamente, uma maior ou menor estruturação do trabalho em redução de danos e, geralmente, um maior ou menor período e montante de investimentos (financeiros, políticos e sociais) na implantação deles.

Para o mapeamento dos programas/ações foram realizadas entrevistas individuais com as coordenações de cada programa no local onde o programa se estabelece, pelo uso de um questionário semi-estruturado, testado em entrevistas-piloto. $\mathrm{O}$ intuito das entrevistas foi conhecer o funcionamento e a organização dos programas, tendo como foco o trabalho e sua sustentabilidade. Sustentabilidade é compreendida aqui como o apoio político, técnico-administrativo e financeiro necessário à continuidade das ações de redução de danos implantadas pelos programas. Foram entrevistados ainda dois representantes do CRRD-ESP/RS e um da Associação Brasileira de Redutores de Danos (ABORDA). As entrevistas foram gravadas e transcritas para análise das respostas. Também compõem o corpus da pesquisa documentos referentes à legislação e às políticas públicas referentes ao período de 1976 a 2005, e, ainda, reportagens publicadas na imprensa entre 2004 e 2005. Todos os participantes da pesquisa assinaram o termo de consentimento esclarecido, e o projeto de pesquisa obteve aprovação do Comitê de Ética em Pesquisa da Universidade Federal do Rio Grande do Sul. Houve um debate com os entrevistados interessados em torno das conclusões preliminares como forma de validação 17 .

\section{Resultados}

A Tabela 1 resume as categorias utilizadas para a descrição e comparação dos programas. Uma análise mais detalhada de cada ação e programa pode ser encontrada em Rigoni 7.

Pode-se observar uma grande diversidade de formas de organização dos programas/ações em redução de danos na Região Metropolitana de Porto Alegre. Dividimos os 11 locais analisados tendo como base sua estrutura (PRD ou ações) e vínculo (ONG ou organização governamental) em quatro categorias: $\mathrm{PRD}$ vinculados à organização governamental e PRD vinculados às ONG; ações vinculadas à organização governamental $\mathrm{e}$ ações vinculadas às ONG. Na Tabela 1, observase que do total de 11 locais analisados, sete eram estruturados em PRD e quatro possuíam Ações, sendo cinco vinculados à organização governamental e seis às ONG.

O tempo de funcionamento dos programas/ ações variou desde um mínimo de quatro anos até um máximo de dez (tendo como base o ano de 2006). Para os programas da Região Metropolitana de Porto Alegre, entretanto, a atuação há mais de quatro anos não representou garantia de uma estabilidade no exercício de suas ações.

As duas localidades com ações vinculadas às ONG estão ligadas às primeiras experiências de redução de danos no estado (em tempo de atuação e proximidade). Apesar disso, não possuem financiamento, contando apenas com o trabalho voluntário de lideranças comunitárias e pessoas abordadas na comunidade. Em raros momentos houve financiamento do Ministério da Saúde para ações pontuais. Nestes casos, a contratação dos trabalhadores deu-se por Recibo de Pagamento a Autônomo (RPA). Mesmo com um trabalho basicamente voluntário, as ações se mantêm em funcionamento, e ambas as localidades fazem-se representar em espaços políticos como: associações de bairro, conselhos de entorpecentes e o Fórum Metropolitano de Redução de Danos (FMRD). Este último, criado ao final de 2003 pelos trabalhadores de PRD/ações da Região Metropolitana de Porto Alegre, surge por causa da necessidade de promover o intercâmbio entre as instituições que realizam ações de redução de danos na Região Metropolitana de Porto Alegre. O FMRD tem caráter consultivo e atua como espaço de articulação política entre a sociedade civil organizada e o Estado, sendo composto pelas representações das diversas entidades que trabalham com redução de danos na Região Metropolitana de Porto Alegre, por uma representante da SE-DST/AIDS e outra do CRRDESP/RS. Suas discussões incluem: a continuidade das ações, os apoios político, financeiro e técnico 
Mapeamento dos programas/ações de redução de danos.

\begin{tabular}{|c|c|c|c|c|}
\hline & $\begin{array}{c}\text { PRD vinculados à } \\
\text { organização governamental }\end{array}$ & $\begin{array}{l}\text { PRD vinculados } \\
\text { às ONG }\end{array}$ & $\begin{array}{c}\text { Ações vinculadas à } \\
\text { organização governamental }\end{array}$ & $\begin{array}{c}\text { Ações vinculadas } \\
\text { à ONGs }\end{array}$ \\
\hline Quantidade & 3 & 4 & 2 & 2 \\
\hline Tempo de funcionamento & 4,6 e 10 anos & $4,6,8$ e 9 anos & 4 e 6 anos & 8 e 9 anos \\
\hline \multirow[t]{2}{*}{ Financiamento } & $\operatorname{Sim}(1)$ & Sim, mas com atraso & Sim & Não \\
\hline & Não específico (2) & & & \\
\hline \multirow[t]{3}{*}{ Financiador atual } & PAM Saúde Mental (1) & PAM DST/AIDS * (2) & PAM DST/AIDS - & - \\
\hline & Prefeitura "não específico" (2) & Ministério da Saúde ** (1) & contratação de ONG & \\
\hline & & Prefeitura convênio (1) & & \\
\hline \multirow[t]{2}{*}{ Em funcionamento } & Sim & $\operatorname{Sim}(3)$ & Não & Sim \\
\hline & & Não (1) & & \\
\hline \multirow[t]{2}{*}{ Contrato } & Funcionário cedido (2) & RPA & RPA & - (voluntários) \\
\hline & RPA (1) & & & \\
\hline \multirow[t]{3}{*}{ Critério de entrada } & Indicação (2) & Voluntários, abordagens na & Licitação - ONG & Lideranças comunitárias, \\
\hline & Seleção para redutores (1) & 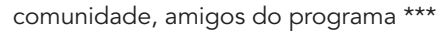 & Concurso - agentes & abordagens na \\
\hline & & & comunitários de saúde & comunidade, voluntários \\
\hline \multirow[t]{3}{*}{ Voluntariado } & Não (1) & Sim. Equipe em períodos & Sim, por parte de ONG & Sim \\
\hline & Sim, nos períodos com & de atraso de recursos e & & \\
\hline & atraso de repasse (2) & amigos do programa & & \\
\hline \multirow[t]{2}{*}{ Representação política } & Não (2) & Não (1) & Não & Sim \\
\hline & $\operatorname{Sim}(1)$ & $\operatorname{Sim}(3)$ & & \\
\hline
\end{tabular}

PRD: Programa de Redução de Danos; ONG: organização não governamental; PAM: Posto de Atendimento Médico; RPA: Recibo de Pagamento a Autônomo.

* Plano de ações e metas do Serviço Municipal de DST/AIDS;

** Ministério da Saúde, pela concorrência de projetos:

*** O "amigo do projeto" ou "amigo do programa" é uma pessoa da comunidade que se dispõe a auxiliar o redutor em seu trabalho, guardando materiais (seringas, cachimbos, preservativos) em sua casa para trocas ou distribuição em horários que o redutor não se encontra no campo. O amigo também auxilia acessando os usuários que (ainda) não querem aparecer para o PRD.

necessários, a avaliação e monitoramento dos projetos em redução de danos de seus filiados e as representações políticas do movimento de redução de danos, discussões fundamentais para o direcionamento, qualidade e possibilidade das ações em redução de danos na Região Metropolitana de Porto Alegre.

Em duas das localidades onde havia um PRD vinculado à organização governamental também não encontramos um financiamento específico para as ações em redução de danos. Porém, os programas contavam com um local e um ou dois funcionários cedidos (parcialmente) para o trabalho, ficando a negociação dos insumos - preservativos femininos e masculinos, folders, informativos, seringas, swabs, pote para diluição, água destilada e cachimbos - na pendência da "boa vontade" de outros programas existentes no município. Os dois locais sofreram uma drástica redução de recursos disponíveis (humanos, financeiros e materiais), e conseqüentemente das ações e parcerias estabelecidas, comparativamente à análise realizada em 2003 13. Tal redução deu-se por ocasião do término, em 2004, do financiamento de projetos até então aprovados pelo Ministério da Saúde, sem que houvesse a prevista integração das ações pelos municípios através dos Postos de Atendimento Médico (PAM), ficando prejudicadas as ações e a comunidade atendida.

As coordenações relataram modificações nos interesses político-partidários dos municípios e em cargos de coordenações na área da saúde e nos programas de DST/AIDS, em função da troca de gestão na eleição municipal de 2004. Na nova configuração, o investimento (humano, fi- 
nanceiro e material) nos programas em redução de danos passou a não mais constar no planejamento do governo, dificultando a continuidade do trabalho. Como o critério de entrada no PRD dos funcionários cedidos para o trabalho era a indicação político-partidária, a modificação de cargos e interesses ocasionou alterações no direcionamento e continuidade do trabalho. Em um dos casos houve o afastamento e demissão de toda equipe que executava o trabalho. Em 2006, as localidades não participavam de espaços de representação política no que tange às políticas públicas em saúde e/ou drogas.

Em ambos os casos, os coordenadores citaram a dificuldade de convencer os gestores a investirem recursos na população "usuários de drogas", especialmente no caso de se tratar de uma abordagem em que não há uma exigência obrigatória relacionada à abstinência. Segundo os coordenadores, o gestor acredita que este tipo de ação "não gera votos", e pode trazer a idéia de que o município "apóia o uso de drogas". Vemos aí que noções equivocadas sobre a proposta da redução de danos e o preconceito que circunda o uso de drogas podem influenciar a vontade política para a (falta de) continuidade das ações.

Na terceira localidade com PRD ligado à organização governamental havia um financiamento específico para o PRD durante quase todo seu tempo de vida, excetuando-se o início, quando o trabalho era voluntário. Em 2006, os recursos financeiros eram repassados pelo PAM do município, vinculada ao Serviço de Saúde Mental. Os trabalhadores eram contratados por RPA e os critérios para entrada no programa eram indicação técnico-política para coordenação e processo seletivo para redutores de danos. Há períodos de trabalho voluntário por parte da equipe durante os atrasos no repasse dos recursos. Da mesma forma, o programa conta com o trabalho voluntário dos amigos do programa para ampliar o espaço de suas ações. Os espaços de representação política freqüentados incluem o FMRD e reuniões entre Secretarias.

Também neste programa ocorreram modificações em função de uma mudança de gestão. Neste caso, a mudança culminou na não-renovação dos contratos dos trabalhadores e na permanência do PRD na situação de inativo por alguns meses, correndo o risco de ser fechado. Durante o período, muitos atuaram de forma militante dando continuidade ao trabalho voluntariamente e denunciado a situação em que os trabalhadores e a população atendida se encontravam. Com tal movimentação interna e com pressões exteriores (locais parceiros do PRD), os contratos foram renovados. Neste período, contudo, ocorreram demissões de trabalhadores e modifica- ções no direcionamento do trabalho proposto, com a tentativa da nova coordenação de incluir idéias contrárias à perspectiva da redução de danos, trazendo conseqüências para a comunidade atendida e para os trabalhadores. Neste caso, entretanto, houve uma maior habilidade da equipe em lidar com as questões relativas à sustentabilidade, o que talvez se deva ao fato de o programa ter um maior período de funcionamento, além de uma estrutura de repasse de recursos bem definida desde a sua criação.

Nos dois locais com Ações vinculadas à organização governamental, o financiamento para o trabalho estava incluído no PAM, com recursos do Serviço Municipal de DST/AIDS (SMDST/AIDS). Em ambas as localidades as ações em redução de danos iniciaram-se pelo trabalho voluntário de uma ONG, que depois obteve financiamento do Ministério da Saúde para um projeto de capacitação de agentes comunitários de saúde para a inserção da redução de danos nos serviços de Atenção Básica do município. Mediante a sensibilização promovida pela ONG deu-se a inserção da redução de danos no PAM com recursos do SM-DST/AIDS. Não obstante o financiamento, as ações em redução de danos se encontravam praticamente paradas nestes dois municípios em função da abertura de um processo de licitação para contratação de ONG para realizar o trabalho; porém os agentes comunitários de saúde municipais continuavam realizando ações no seu trabalho diário. Nenhum dos locais possuía, em 2006, representação política nos espaços referentes ao campo de ação.

Por fim, os dois PRD vinculados às ONG contavam com financiamento pelo PAM do SM-DST/ AIDS: um pelo Ministério da Saúde e outro com convênio via Prefeitura. Os trabalhadores eram contratados por RPA, sendo o principal critério para contratação a priorização daqueles que já realizaram trabalho voluntário como amigos do programa. Esta característica acaba por reforçar o trabalho voluntário, adotado e defendido por grande parte dos trabalhadores em redução de danos. Embora possuíssem financiamento, todos os PRD vinculados às ONGs enfrentavam dificuldades financeiras em função de um atraso considerável no repasse de recursos. Em um dos PRD a equipe se encontrava impossibilitada de trabalhar devido à falta de recursos. As demais localidades contavam com a militância dos redutores de danos e coordenações, que se esforçavam para dar continuidade às ações apesar da falta de salário e recursos para compra de insumos. Em alguns locais o atraso no recebimento já ultrapassava seis meses.

Nas duas localidades que contavam com o financiamento via PAM, o programa iniciou 
com o trabalho parcialmente voluntário das ONG, passando, a seguir, a obter financiamento do Ministério da Saúde. No primeiro semestre de 2005 esses PRD fizeram parte dos "projetos de transição" do Ministério da Saúde. Tais projetos eram financiados pelo Ministério da Saúde (através do Programa Nacional e Estadual de DST/AIDS) por seis meses durante o ano de 2005, período durante o qual deveriam negociar a inserção de suas ações em redução de danos nos PAM municipais. Os projetos se inseriam na estratégia de descentralização do financiamento, monitoramento e avaliação das ações. Após a sensibilização continuada dos gestores municipais, as duas localidades obtiveram êxito na inserção no PAM através do SM-DST/AIDS. O recurso, no entanto, ainda não havia sido liberado. Já a localidade que contava com o financiamento do Ministério da Saúde antes do final dos projetos de transição, não conseguiu sucesso nas negociações. Os trabalhadores mantiveram as ações voluntariamente por um período, ficando depois disso desarticuladas. Segundo a coordenação, a falta de vontade política e os "problemas burocráticos" impediram a continuidade do programa.

O PRD que obteve convênio da prefeitura acabou devido ao atraso de repasse e a modificações de gestão política, paralisando suas atividades para passar por uma reestruturação. $\mathrm{O}$ atraso de repasse, segundo a coordenação, devia-se a problemas financeiros enfrentados pelo município, já a mudança de gestão influenciou no apoio político dado à estratégia da redução de danos, tendo sido privilegiados programas cuja estratégia principal era abstinência. Apenas um local não participava de instâncias de representação política. Os demais se inseriam no FMRD e em Conselhos de Entorpecentes.

As atividades realizadas se mostraram semelhantes nos locais abordados, excetuando-se as duas localidades com ações vinculadas à organização governamental, o que parece decorrer da inexistência de redutores de danos nestas localidades no período estudado. As atividades nestes locais centravam-se naquelas realizadas por agentes comunitários de saúde em seu cotidiano: encaminhamento para centros de testagem, aconselhamento e tratamento em HIV/AIDS, abordagens nas escolas, intervenções na comunidade, troca de seringas pontuais. Já as atividades de campo dos redutores de danos incluíam, além das acima citadas: encaminhamento para consultas e tratamento em dependência química, aconselhamento, visita domiciliar, trocas de seringas, abordagem de usuários de crack (com ou sem troca de cachimbos), distribuição de insumos, informação para comunidade, plantões na sede do programa, abordagem de profissionais do sexo, população carcerária, moradores de rua, capacitação de equipes de saúde (dentre eles, os agentes comunitários de saúde), vacinação para hepatites, oficinas de geração de renda, atividades culturais, terapia comunitária, reunião de equipe, participação em eventos de capacitação, grupo de estudos, participação em Conselhos, dentre outros. Uma das dificuldades encontradas pelos redutores de danos se refere à falta de uma supervisão de campo não atrelada à coordenação, que possa oferecer um espaço de reflexão e discussão acerca das mobilizações emocionais produzidas pelo seu trabalho.

Com relação às parcerias estabelecidas dentro e fora da comunidade, as mais comumente citadas foram: SM-DST/AIDS, PACS, PSF, Conselho Municipal de Saúde, SM-Saúde Mental, Secretaria Municipal de Educação, associações comunitárias, hospitais, universidades, presídios, ONG que atendem populações específicas (moradores de rua, crianças, profissionais do sexo, gays, lésbicas e travestis). Foram citadas ainda, em menor grau: universidades, comunidades terapêuticas, Alcoólicos Anônimos (AA) e Narcóticos Anônimos (NA), postos de gasolina, Departamento Estadual de Trânsito (DETRAN), Programa Fome Zero. Mudanças ou quebras bruscas nas parcerias estabelecidas foram observadas pelos participantes por ocasião de trocas de gestão governamental quando, muitas vezes, os trabalhadores são obrigados a reconstituir parcerias por intermédio de sensibilizações e negociações, percebidas por eles como "intermináveis".

A infra-estrutura dos programas/ações é muito diversa, podendo ou não ter um local específico: uma sala cedida, uma sala própria, uma casa, ou a inexistência de um local. Onde há um local, geralmente o $\mathrm{PRD} /$ ação possui telefone, computador, impressora, som, máquina fotográfica, fax, móveis e insumos para o trabalho. Televisão, vídeo e automóveis foram os equipamentos menos citados (dois locais). A equipe nos locais geralmente contava com uma quantidade variável de redutores de danos, voluntários, amigos do projeto, bem como de uma coordenação. A exceção novamente veio dos locais com ações vinculadas à organização governamental, em que o trabalho era predominantemente realizado por agentes comunitários de saúde nos períodos sem financiamento específico, em que a equipe da ONG não atuava. Podese observar uma diminuição no número de pessoas atuantes em períodos de atraso de repasse mais longos, quando o trabalhador acaba tendo que largar sua função de redutor de danos para buscar seu sustento em outra atividade. 


\section{Discussão}

O financiamento para os programas/ações em redução de danos se mostrou atrelado à política de DST/AIDS, excetuando-se apenas um programa em que a ligação se deu com a saúde mental. Este vínculo preferencial com a AIDS se deve ao histórico das ações de redução de danos no Brasil, as quais tiveram início em âmbito local, mas somente ganharam força com o apoio técnico e financeiro do Ministério da Saúde pelo Programa Nacional de DST e AIDS (PNDST/AIDS) e com apoio do Banco Mundial. No país, a história da redução de danos aponta para abordagens específicas ligadas à prevenção da AIDS no que tange à “categoria de exposição” UDI 3 .

O recurso para o financiamento é público em todos os locais; é público, seja do Ministério da Saúde por intermédio de projetos, seja das Prefeituras Municipais pelos convênios ou PAM da SM-DST/AIDS ou SM-Saúde Mental, não havendo referência a recursos de capital privado. Estes resultados se assemelham àqueles do estudo de Fonseca et al. ${ }^{11}$ em que nos 45 PRD analisados no país a principal fonte de financiamento está no governo, predominantemente na esfera federal. Na maioria dos municípios a redução de danos iniciou-se pelo trabalho voluntário, geralmente de alguma ONG. Comumente, esta é uma fase de inserção das ações na qual é priorizada a sensibilização de gestores e equipes de saúde, além do trabalho de mapeamento de locais e necessidades no campo em questão. Nos locais onde o início foi voluntário, obteve-se financiamento do Ministério da Saúde logo após. Os locais que já iniciaram com financiamento, também o obtiveram primeiramente junto ao Ministério da Saúde, oriundo dos recursos destinados à prevenção das DST/AIDS.

A maioria dos coordenadores relatou ter sofrido atrasos no repasse de recursos em algum momento, o que acabou prejudicando o trabalho. Segundo os coordenadores, os problemas com repasse não se devem a dificuldades na prestação de contas, mas à ausência de vontade política. Entretanto, em alguns momentos "problemas burocráticos" foram mencionados, o que pode indicar uma dificuldade em dar conta das exigências técnicas referentes ao repasse, embora não tenhamos dados suficientes para comprovar esta afirmação.

Outro ponto importante que se refere à (des)continuidade das ações em redução de danos foram os chamados "projetos de transição". A passagem do financiamento por projetos (Ministério da Saúde) para a inserção no PAM municipal foi estimulada pelo PNDST/AIDS e SM-DST/AIDS. Esse processo de descentrali- zação, todavia, não contou com apoio político e técnico-administrativo suficiente por parte do Estado, que deixou as negociações para a inserção das ações, em sua maioria, na mão das ONG que desenvolviam os projetos. Muitos locais tiveram dificuldades por desconhecer os caminhos da negociação, fato que gerou o desemprego de trabalhadores e uma desestruturação do atendimento à população. Esses dados nos mostram que, apesar da ampliação do incentivo político e financeiro que vem sendo dado às ações de redução de danos por parte do governo, o apoio ainda se mostra insuficiente para garantir a continuidade e a inserção das ações. O início e a manutenção do trabalho em redução de danos na Região Metropolitana de Porto Alegre depende ainda, em grande parte, da militância e do trabalho voluntário de redutores de danos e coordenadores, o que coloca a população atendida, os programas e seus trabalhadores em uma posição de fragilidade e precarização do trabalho.

Em muitas ocasiões o trabalho voluntário sustenta as ações em campo durante os períodos com atraso no repasse, porém, com atrasos prolongados geralmente diminui-se o número de integrantes nas equipes e, por vezes, o trabalho pára, pois os trabalhadores têm que ser liberados para conseguir seu sustento em outros locais 7. O próprio critério de entrada dos trabalhadores acaba por perpetuar esta forma de trabalho, já que muitos são contratados após terem realizado um trabalho voluntário como amigos do programa.

A quase totalidade dos trabalhadores, com exceção daqueles cedidos pelas prefeituras, é contratado como autônomo, não possuindo acesso às garantias da legislação trabalhista: férias, 13o salário, seguro saúde, seguro desemprego, fundo de garantia etc.; e possuindo aposentadoria apenas em caso de contribuição individual ao INSS (Instituto Nacional do Seguro Social) 7. Também em nível nacional esses resultados se mostram semelhantes. Segundo Fonseca et al. 11, 55\% dos trabalhadores dos 45 programas avaliados são contratados como autônomos e $31 \%$ são voluntários. Somente $7 \%$ possuem formas de contratação mais estáveis como vínculo de servidor público ou contrato por CLT (Consolidação das Leis do Trabalho).

Para fugir da precarização do trabalho e fragilidade dos programas, o movimento social em redução de danos tem pensado na inserção institucional das ações no SUS. O debate com relação às conseqüências possíveis neste sentido é amplo, e não é nosso foco neste artigo. Contudo, os dados produzidos na Região Metropolitana de Porto Alegre nos possibilitam dizer que a 
inserção de um PRD ou ação no SUS mediante o trabalho dos agentes comunitários de saúde ou da inserção no PAM municipal está longe de garantir a sustentabilidade e estabilidade dos programas, trabalhadores, e atendimento à população. Tanto as organizações governamentais quanto as ONG sofrem com os atrasos no repasse do recurso e/ ou dificuldades de financiamento, o que por si já prejudica o andamento do trabalho. Porém, uma questão que só foi encontrada na organização governamental é a possibilidade da descontinuidade da linha de trabalho em função das trocas de gestão. Diferentemente da ONG, a troca de gestão municipal da organização governamental acarreta uma troca na equipe e coordenação do programa, ficando a cargo dessas novas pessoas o modo de continuar o trabalho. Assim, tanto a posição político-partidária quanto a opção pessoal da coordenação no que se refere às diferentes abordagens para lidar com o uso/ abuso de drogas podem dificultar ou mesmo impossibilitar o trabalho em razão da perspectiva da redução de danos.

Com as eleições municipais de 2004, ocorreu uma troca de gestão (nem sempre de partido, mas de pessoas) em oito dos nove municípios analisados. Tais trocas, em diversos casos, dificultaram ou inviabilizaram as parcerias existentes por terem ocorrido mudanças de coordenações e secretarias. Dentro do amplo quadro de atividades realizadas pelos PRD, como relatado anteriormente, pode-se perceber que as parcerias estabelecidas dentro e fora da comunidade são de grande importância para garantir a integralidade das ações. Por conseguinte, novas sensibilizações tiveram de ser feitas na tentativa de garantir apoio.

Um dos fatores importantes para a inserção e manutenção das ações nos municípios é a negociação com os gestores. Em função da visibilidade negativa que os usuários de drogas têm na sociedade e também da diferenciação da proposta da redução de danos em relação às estratégias focadas na abstinência, muitas vezes há uma dificuldade "extra" na negociação de apoio político-financeiro ${ }^{12}$. Com a descentralização do repasse de verbas para as ações/programas em redução de danos, as instituições executoras têm de sair da esfera federal e disputar seus projetos no âmbito estatal e municipal, em que gestores locais têm autonomia para decidir ou não investir em redução de danos. Nesse contexto, a hipótese de um aumento de vetos/constrangimentos políticos no plano estadual e municipal, inclusive derivada de grupos religiosos ou lideranças conservadoras refratárias às praticas da redução de danos já havia sido levantada por Fonseca et al. 18 para o caso do Rio de Janeiro, e tal dificulda- de parece confirmar-se na Região Metropolitana de Porto Alegre.

Vale dizer que a Região Metropolitana de Porto Alegre é a região do Rio Grande do Sul que possui o maior coeficiente de prevalência (3050 por 10 mil habitantes) para casos de AIDS. O número de novos casos no RS no ano de 2007 em UDI masculinos e femininos adultos representou, respectivamente, $18,4 \%$ do total de casos (238) e 5,6\% (54 casos). No ano de 1996, quando se iniciaram as ações de redução de danos no estado, o número de casos de AIDS para UDI masculino e feminino eram, respectivamente, $35,5 \%$ (478) e 16,9\% (104 casos) (Secretaria da Saúde do Estado do Rio Grande do Sul; http://www. saude.rs.gov.br/wsa/portal/index.jsp?menu =organograma $\& \operatorname{cod}=1158$, acessado em 14/ Abr/2008). Assim, apesar da relevância epidemiológica da categoria UDI no estado, talvez a diminuição de novos casos de AIDS nesta população com o passar dos anos e o aumento de casos relacionados a relações sexuais desprotegidas na população heterossexual, no ano de 2007, responsável por $40,6 \%$ do total de casos masculinos e $83,1 \%$ de casos femininos, pode fazer com que os gestores estejam priorizando outras áreas de ação que não as de prevenção com UDI.

Para além do interesse político-partidário do gestor municipal, a fragilidade das equipes e coordenações dos programas também denota a necessidade do desenvolvimento de competências específicas para lidar com a descentralização do financiamento, incluindo um maior conhecimento sobre o novo mecanismo de repasse e a criação de estratégias de sustentabilidade neste sistema. O exercício de negociação é ainda pouco desenvolvido para grande parte dos trabalhadores em redução de danos. No entanto, comparando a análise realizada em 2003 com os dados produzidos em 2006, podemos ver um aumento referente à participação política destes trabalhadores.

A criação do FMRD no final de 2003 proporcionou um espaço de debate acessado por muitos locais, incentivando uma ampliação de espaços de negociação, particularmente nos Conselhos de Entorpecentes e Associações de Bairro. A participação ainda é tímida e mais freqüente nos locais com ações/programa de ONG, fortalecendo a idéia de que a militância tem se mostrado fundamental para a inserção, manutenção e ampliação da redução de danos. Por "militância" entende-se, segundo relato dos participantes, a ação de seguir e defender as idéias e conceitos presentes na proposta da redução de danos, tanto no espaço de trabalho como fora dele 7 .

Com relação à legislação, apenas dois municípios possuem leis que dão sustentação jurí- 
dica ao trabalho com seringas, mas a existência da Lei estadual já regulamenta este trabalho 5 . A Lei estadual, no entanto, não regulamenta o trabalho com cachimbos ou outros insumos que venham a ser adotados; portanto podem ocorrer intervenções policiais que visam os redutores de danos e/ou usuários nos municípios onde se trabalha com a adoção de cachimbos. Além da legitimidade do trabalho perante as possíveis abordagens policiais, a existência da legislação municipal garante a legitimidade do PRD, protegendo as ações e os trabalhadores em caso de questionamento comunitário ou institucional, podendo servir como mais um instrumento na luta pela sustentabilidade.

Significa afirmar que a legislação já existente foi articulada e estabelecida por meio da participação de militantes do movimento social em redução de danos na sensibilização de gestores, conselheiros, vereadores e deputados. Se avaliarmos que há dez anos não era possível pensar uma estratégia como a redução de danos, e muito menos vislumbrar a existência de um movimento social que defende a cidadania do usuário de drogas, talvez já se tenha avançado bastante, porém não o suficiente. Para Sherer-Warren 19, as maiores dificuldades para implantar ações de cooperação e complementaridade nas parcerias entre o governo e a sociedade civil situam-se no campo da cultura política, ou seja, na forma como o governo estabelece suas relações com a sociedade civil e a forma como esta compreende as ações do governo. Enquanto o Estado possui uma dificuldade de efetivar políticas públicas para além de políticas de governo atreladas a interesses do partido político no poder, a sociedade civil ainda possui uma incipiente organização, havendo grande dificuldade de envolver a população em processos participativos que possibilitem a continuidade das políticas sociais criadas.

É dessa forma que vemos a complexidade inerente à sustentabilidade dos programas e ações em redução de danos, uma vez que, para além da continuidade do financiamento, é necessário também o apoio político contínuo - a fim de sensibilizar gestores para a importância da inserção e/ou manutenção das ações em redução de danos - e também uma continuidade de suporte técnico-administrativo para dar agilidade aos processos burocráticos, efetivo monitoramento e avaliação das ações/projetos em execução (garantido a efetividade das ações e continuidade de uma linha de trabalho), e ainda a capacitação, tanto de organizações governamentais quanto das ONG, para um maior conhecimento dos processos necessários à inserção e continuidade das ações.

Cabe uma observação referente à participação fundamental do trabalho voluntário para as ações. O voluntariado foi reiteradamente afirmado pelos trabalhadores como "parte do trabalho”, fruto de sua militância. Por um lado, podemos pensar o trabalho pela via da militância como uma atividade que possui um significado na vida do trabalhador para além de ser um "meio de sobrevivência". O trabalho passa a ser considerado como uma atividade que visa à transformação de condições sociais percebidas como indignas ou insuficientes pelos trabalhadores, possibilitando ao menos em parte, o exercício da cidadania. Entretanto, esta mesma relação pode acabar sendo utilizada como forma de garantir a necessidade do trabalho voluntário e a "continuidade da descontinuidade". Na medida em que, apesar da precarização do trabalho, os trabalhadores em redução de danos continuam exercendo suas atividades, como chamar a atenção para a necessidade de melhorar as condições deste trabalho?

Talvez possamos considerar as formas de inserção e do trabalho e dos trabalhadores em redução de danos como mais um passo na direção de uma saúde e cidadania possíveis. A plenitude deste processo demandará muitas lutas e combates, associadas à intensificação dos espaços de solidariedade, controle social e de uma retomada do papel do Estado e dos movimentos sociais na construção de um laço social que garanta a integração em uma sociedade que tenha a vida como valor ético central. 


\section{Resumo}

Neste estudo mapeamos e descrevemos 11 programas/ ações em redução de danos vigentes nos anos de 2004 a 2006, na Região Metropolitana de Porto Alegre, Rio Grande do Sul, Brasil. A descrição e análise se construíram por meio de entrevistas com as coordenações dos programas, de análise documental e da comparação com um mapeamento realizado em 2003. Buscou-se discutir a sustentabilidade (política, financeira e administrativa) e as características de funcionamento dos programas. A análise utilizou as seguintes categorias: tipo de vínculo do programalação; formas de inserção nos municípios; histórico, financiamento; ações típicas; forma de contratação da equipe; existência de trabalho voluntário; recursos (humanos e financeiros); parcerias; existência de legislação municipal; e participação em espaços de representação política. Apesar da diversidade de vínculos e formas de organização dos locais analisados, algumas características são comuns, como: inserção profissional precária; dependência do trabalho voluntário para a execução das atividades; influência das mudanças de gestão municipal e estadual para a continuidade de projetos e de parcerias, assim como para a manutenção de recursos humanos e financeiros dos programas. Concluímos que estes elementos geram descontinuidade no atendimento à população.

Redução de Danos; Drogas Ilícitas; Políticas Públicas

\section{Referências}

1. Wodak A. Redução de danos e programas de trocas de seringas. In: Bastos F, Mesquita F, Marques L, organizadores. Trocas de seringas: drogas e AIDS. Ciência, debate e saúde pública. Brasília: Ministério da Saúde; 1998. p. 55-72.

2. Bueno R. Estratégias de redução de danos em Santos, SP. In: Bastos F, Mesquita FE, Marques L, organizadores. Trocas de seringas: drogas e AIDS. Ciência, debate e saúde pública. Brasília: Ministério da Saúde; 1998. p. 163-9.

3. Coordenação Nacional de DST e AIDS. Manual de redução de danos. Saúde e cidadania. Brasília: Ministério da Saúde; 2001.

4. Siqueira D, Winkler G, Barcellos N, Mayer R, Conte M, Fernandez O. O Projeto de Redução de Danos no Rio Grande do Sul. In: Bastos F, Mesquita FE, Marques L, organizadores. Trocas de seringas: drogas e AIDS. Ciência, debate e saúde pública. Brasília: Ministério da Saúde; 1998. p. 171-84.

\section{Colaboradores}

R. Q. Rigoni planejou e construiu o estudo sob orientação de H. C. Nardi. Ambos os autores participaram no desenvolvimento, redação e revisão do manuscrito.
5. Kuchenbecker R, Sudbrack M. Muito além da troca de seringas: a experiência do Programa de Redução de Danos associados ao uso de drogas injetáveis em Porto Alegre. Divulg Saúde Debate 2001; 24:98-105.

6. Estado do Rio Grande do Sul. Projeto de Lei No. 169/99, de 12 de agosto de 1999. http://www.al.rs. gov.br/proposições/199/pl169_99.htm (acessado em 04/Set/2003).

7. Rigoni RQ. Assumindo o controle. Organizações, práticas e a experiência de si em trabalhadores da redução de danos na região metropolitana de Porto Alegre [Dissertação de Mestrado]. Porto Alegre: Programa de Pós-Graduação em Psicologia Social e Institucional, Universidade Federal do Rio Grande do Sul; 2006. 
8. Hunt N, Trace M, Bewley-Taylor D. Reducing drug related harms to health: an overview of the global evidence. Report four. http://www.internation aldrugpolicy.net/reports/BeckleyFoundation Report_04.pdf (acessado em 14/Abr/2008).

9. Van Den Hoek JAR, Van Haastrecht HJA, Coutinho RA. Risk reduction among intravenous drug users in Amsterdam under the influence of AIDS. Am J Public Health 1989; 79:1355-7.

10. Bastos F, Karam M, Martins S. Drogas, dignidade e inclusão social: a lei e a prática de redução de danos. Rio de Janeiro: Associação Brasileira de Redutores de Danos; 2003.

11. Fonseca EM, Ribeiro JM, Bertoni N, Bastos FI. Syringe exchange programs in Brazil: preliminary assessment of 45 programs. Cad Saúde Pública 2006; 22:761-70

12. Nardi HC, Rigoni RQ. Marginalidade ou cidadania? A rede discursiva que configura o trabalho dos redutores de danos. Psicol Estud 2005; 10:165-73.

13. Debacco S, Oliveira J. Análise situacional dos PRD do Estado do Rio Grande do Sul em 2003. Porto Alegre: Centro de Referência para o Assessoramento e Educação em Redução de Danos, Escola de Saúde Pública do Estado do Rio Grande do Sul.
14. Freeman R. Learning in public policy. In: Moran M, Rein M, Goodin R, editors. The Oxford handbook of public policy. Oxford: Oxford University Press; 2006. p. 365-86.

15. Strike CJ, O'Grady C, Myers T, Millson M. Pushing the boundaries of outreach work: the case of needle exchange outreach programs in Canada. Soc Sci Med 2004; 59:209-19.

16. Insua P, Moncada S. Cognitive and behavioral change in health care professionals after training in the treatment of injection drug users. Clin Infect Dis 2003; 15:416-21.

17. Bauer, M, Gaskell, G. Pesquisa qualitativa com texto, imagem e som: um manual prático. Petrópolis: Editora Vozes; 2002.

18. Fonseca EM, Nunn A, Souza-Junior PB, Bastos FI, Ribeiro JM. Descentralização, AIDS e redução de danos: a implementação de políticas públicas no Rio de Janeiro, Brasil. Cad Saúde Pública 2007; 23:2134-44.

19. Sherer-Warren I. Cidadania sem fronteiras: ações coletivas na era da globalização. São Paulo: Editora Hucitec; 1999.

Recebido em 07/Ago/2007

Versão final reapresentada em 31/Jul/2008

Aprovado em 31/Ago/2008 